\title{
Masif rotator manşet yırtıklarında superior kapsüler rekonstrüksiyon ve klinik sonuçları
}

\author{
Superior capsular reconstruction in massive rotator cuff tears and \\ clinical results
}

Yusuf Onur Kızılay

İstanbul Atlas Üniversitesi Tıp Fakültesi Ortopedi ve Travmatoloji Ana Bilim Dalı, İstanbul

\begin{abstract}
Masif rotator manşet yırtıkları cerrahi tedavide ortopedik cerrahlar için birçok zorluğa sebep olabilmektedir. Masif yırtıklar içerisinde özel bir grubu oluşturan onarılamaz düzeydeki rotator manşet yırtıklarının tedavisi için farklı tedavi seçenekleri olmasına rağmen, bu yöntemlerin hepsinin kendine has kısıtlııkları bulunmaktadır. Geçtiğimiz 10 yıl içerisinde tanımlanan ve dünya çapında giderek ilgi artışına sebep olan superior kapsüler rekonstrüksiyon yöntemi, bu kısıtlılıkların bir kısmına çözüm getirebilecek biyolojik ve eklem koruyucu bir cerrahi seçeneğidir. Bununla birlikte, bu yöntemin göreceli olarak yeni bir yöntem olması ve literatürde uzun takipli klinik çalışmalarının kısıtlı olması sebebiyle cerrahi endikasyonlar ve cerrahi teknikte netlik kazanmayan birçok nokta bulunmaktadır. Bu yazıda superior kapsüler rekonstrüksiyon yönteminin cerrahi endikasyonlarından, uygulama tekniğinden, literatürdeki klinik sonuçlar ve tartışmalı konulardan bahsedilecektir.
\end{abstract}

Anahtar sözcükler: rotator manşet yırtığl; onarılamaz; masif; superior kapsüler rekonstrüksiyon; artroskopi; omuz

\begin{abstract}
Massive rotator cuff tears may cause many difficulties for orthopedic surgeons in the surgical treatment. Although there are different treatment options for the treatment of irreparable rotator cuff tears, which constitute a special group among massive tears, all these methods have their own limitations. The superior capsular reconstruction method, which has been defined in the past 10 years and has become increasingly popular around the world, is a biological and joint-sparing surgical option that can overcome some of these limitations. However, since this method is a relatively new method and clinical studies with long follow-up are limited in the literature, there are many points that are not clear in surgical indications and surgical technique. In this article, the surgical indications of the superior capsular reconstruction method, its application technique, clinical results, and controversial issues in the literature will be discussed.
\end{abstract}

Key words: rotator cuff tear; irreparable; massive; superior capsular reconstruction; arthroscopy; shoulder

rının tedavisi ortopedi ve travmatoloji cerrahları için bazı zorlukları da beraberinde getirmektedir. Özellikle gecikmiş vakalara tendonlarda ileri düzeyde retraksiyon (geri çekilme) ve kaslarda yağlı dejenerasyon eşlik ediyorsa bu hasta grubunda cerrahi onarım sonrası yüksek oranda tekrar yırtık gelişme riski oluşmaktadır. ${ }^{[5]} \mathrm{Bu}$ sebeple ileri düzeyde tendon retraksiyonu ve kaslardaki yağlı dejenerasyonun eşlik ettiği yırtıklar (Goutallier evre 3-4) bazı yazarlara göre onarılamaz yırtık olarak kabul edilmektedir. ${ }^{[5]}$ Bazı yazarlara göre ise cerrahi esnasında gerekli gevşetmeler uygulandıktan sonra tüberkulum majustaki anatomik yapışma bölgesine gerilimsiz olarak dikilemeyen yırtıklar onarılamaz yırtık olarak kabul edilmektedir. ${ }^{[6]}$

iletişim / Contact: Dr. Öğr. Üyesi Yusuf Onur Kızılay•E-posta / E-mail: onurkizilay@yahoo.com

ORCID iD: Yusuf Onur Kızılay, 0000-0001-8373-3426

Geliş / Received: 26 Kasım 2021 • Kabul / Accepted: 27 Ocak 2022 
Onarılamaz kabul edilen yırtıklar için kısmi onarım, otojen ya da allogreftler kullanılarak uygulanan güçlendirilmiş onarımlar, subakromiyal boşluğu dolduran implantlar, latissimus dorsi gibi tendon transferleri ve en son seçenek ters omuz protezi gibi tedaviler denenmesine rağmen tüm bu yöntemlerin kendine has olan kısıtlılıklarından dolayı kusursuz bir tedavi yöntemi tespit edilememiştir. [6] 2013 yılında Mihata ve ark. onarılamaz yırtıkların tedavisinde görülen bu kısıtlılıkların üstesinden gelebilecek "superior kapsüler rekonstrüksiyon (SKR)" adını verdikleri, uyluktan alınan geniş bir fasya lata greftinin artroskopik olarak glenoid ve tüberkulum majus arasına transferi prensibine dayanan bir cerrahi yöntem tarif etmişlerdir. ${ }^{[7]}$ Bu yöntem bazı özellikleri sebebiyle daha önce uygulanmış cerrahi tekniklere göre bazı avantajlara sahiptir. Mihata ve ark., klinik çalışmalarından önce yayımladıkları biyomekanik çalışmada, superior kapsülün kalın bir biyolojik greft ile rekonstrükte edilmesinin, humerus başının eklem hareketleri esnasındaki superior stabilitesini yama greftler ile rotator manşetin onarılmasına göre daha iyi sonuç sağladığını bildirmişlerdir. ${ }^{[8]} \mathrm{Bu}$ anlamda SKR, humerus başının tamamen örtünmesine olanak vererek kısmi onarıma göre avantaj sağlamaktadır. Büyük ve karmaşık cerrahi yaklaşımlara gerek olmaması ve artroskopik olarak uygulanabilmesi sebebiyle latissimus dorsi gibi tendon transferlerine göre de üstün olarak görünmektedir. Yine bu yöntem, ameliyat sonrası rehabilitasyon açısından da tendon transferlerine üstünlük sağlamaktadır. Superior kapsüler rekonstrüksiyon, subakromiyal doldurucu implantlara göre daha biyolojik olması ve ters omuz protezinin aksine eklem koruyucu bir cerrahi seçenek olması nedeniyle özellikle genç-orta yaş hastalarda tercih sebebidir. Birçok farklı çalışmada tatminkâr sonuçları bildirilmiş olsa da her yöntemde olduğu gibi özellikle SKR yönteminde de cerrahi endikasyonların doğru belirlenmesi ve hasta seçiminin doğru yapılması cerrahi başarı açısından temel faktördür. Bu yazıda SKR yönteminin cerrahi endikasyonları, hasta seçimi, cerrahi teknik, ameliyat sonrası rehabilitasyon ve literatürdeki klinik sonuçlar üzerinde durulacaktır.

\section{ENDIKASYONLAR}

Superior kapsüler rekonstrüksiyon göreceli olarak yeni bir cerrahi yöntem olması sebebiyle literatürdeki uzun dönemli çalışma sayısı kısıtlıdır. Bunun sonucu olarak bu yöntemin cerrahi endikasyonları netlik kazanmamıştır. Güncel bilgiler ışığında SKR için en uygun hasta grubunu, bir dizi ameliyat dışı tedaviye rağmen hasta tarafından kabul edilemeyecek düzeyde ağrı ve fonksiyon kaybı olan masif ve onarılamayacak düzeyde yırtığı olan hastalar oluşturmaktadır. ${ }^{[9]}$ Superior kapsül rekonstrüksiyon daha çok postero-superior yani supraspinatus ve infraspina- tus kasını içine alan yırtıklar için uygun bir yöntemdir. Superior kapsül rekonstrüksiyon humerus başını statik olarak stabilize etmesinden dolayı bu yöntemi uygulayabilmek için omzu hareket ettirmek için gerekli olan kuvvet çiftinin (force couple) fonksiyonel olması gerekmektedir. $\mathrm{Bu}$ anlamda teres minör ve daha sık olarak yırtıkla karşımıza gelen subskapularis tendonunun sağlam ya da onarılabilir olması gerekmektedir. Yine omuz elevasyonunu asıl olarak sağlayan aksiller sinir ve innerve ettiği deltoid kasının fonksiyonel olması bu yöntemin uygulanabilmesi için gereken temel şartlardan biridir. Bununla birlikte glenohumeral osteoartritin bulunmaması gerekmektedir. Humerus başının belirgin olarak superior yönde migre olduğu durumlarda (hamada sınıflaması evre 3-4-5) bu yöntem önerilmemektedir. Klinik ve radyolojik olarak anterosuperior kaçma (anterosuperior escape) tespit edilen hastalarda bu yöntem humerus başını stabilize etmede yetersiz kalmaktadır. Superior kapsül rekonstrüksiyonu, endikasyonu kesin olarak ameliyat esnasında rotator manşetin mobilitesi ve subskapularis kasının durumu değerlendirilerek konulabilir. Gerekli ve yeterli rotator manşet mobilizasyonu sonrası gerilimsiz bir biçimde rotator manşetin tüberkulum majustaki anatomik yapışma bölgesine getirilebilen yırtıklar onarılamaz olarak kabul edilmemektedir. Bu tip yırtıklarda gevşetmeler sonrası mediyal tek sıra onarım veya kısmi onarım gibi primer onarım teknikleri denenebilir. Ancak ameliyat öncesi manyetik rezonans (MR) görüntülerinde rotator manşet kaslarında ileri düzey yağlı dejenerasyon (Goutallier evre 3-4) izlenen ve ameliyat esnasında doku kalitesi düşük olarak gözlenen hastalarda tekrar yırtık gelişme riski yüksek olmasından dolayı rotator manşet onarılabilir olmasına rağmen SKR ameliyatı tercih edilebilir. Superior kapsül rekonstrüksiyonunun endikasyon ve kontrendikasyonları Tablo 1'de özetlenmiștir. ${ }^{[9]}$

\section{CERRAHI TEKNIK}

Superior kapsül rekonstrüksiyon tekniğini ilk tarif eden araştırmacılar Mihata ve ark., aynı makalelerinde hastayı yan yatar pozisyonda hazırladıklarını bildirmişlerdir. ${ }^{[7]}$ Yan yatar pozisyonda hastanın omuz bölgesi artroskopiye uygun bir biçimde steril olarak hazırlanır ve örtülür. Yine aynı şekilde hastanın üstte kalan uyluk bölgesi steril olarak hazırlanır ve greft alınmasına izin verecek şekilde geniş bir biçimde örtülür. Yan yatar pozisyonda omuz artroskopisine aşina olmayan cerrahlar önce hastayı yan yatırıp hastadan fasya lata greftini aldıktan sonra greftin hazırlık aşamasında hastayı oturur pozisyona alıp cerrahiye devam edebilir. Biz kliniğimizde, ameliyat öncesi hasta değerlendirmesinde kesin SKR endikasyonu koyduğumuz hastaları önce yan yatırıp fasya lata greftini alıp uyluktaki insizyonu kapattıktan sonra hastayı oturur pozisyona alıp cerrahi 
Tablo 1. Superior kapsüler rekonstrüksiyonunun endikasyon ve kontrendikasyonları ${ }^{[9]}$

\begin{tabular}{ll}
\hline SKR Endikasyonları & \multicolumn{1}{c}{ SKR Kontrendikasyonları } \\
\hline $\begin{array}{l}\text { Masif-onarılamaz düzeyde posterosuperior (supraspinatus + infraspi- } \\
\text { natus) rotator manşet yırtığı }\end{array}$ & Gerilimsiz biçimde primer onarılabilir yırtık \\
$\begin{array}{l}\text { Ameliyat esnasında rotator manşetin anatomik yerine gerilimsiz } \\
\text { olarak getirilememesi }\end{array}$ & $\begin{array}{l}\text { Humerus başında ileri düzeyde superior migrasyon ve akromio-hume- } \\
\text { ral mesafede ileri düzeyde daralma (Hamada evre 3-4-5) }\end{array}$ \\
$\begin{array}{l}\text { Rotator manşet kaslarında ileri düzeyde yağlı dejenerasyon (Goutal- } \\
\text { lier evre 3-4) }\end{array}$ & Gleno-humeral osteoartrit \\
$\begin{array}{l}\text { Humerus başında ileri düzey superior migrasyon ve akromio-humeral } \\
\text { mesafede belirgin daralma olmaması (Hamada evre 1-2) }\end{array}$ & Akromio-humeral osteoartrit/aşınma \\
Sağlam ya da onarılabilir düzeyde subskapularis tendonu & Onarılamaz düzeyde subskapularis yırtığı \\
\hline SKR: Superior kapsüler rekonstrüksiyonu. & Aksiller sinir lezyonu ya da deltoid disfonksiyonu
\end{tabular}

işleme devam etmekteyiz. Eğer hastada rotator manşette primer onarım intimali varsa, hastanın oturur pozisyonda karşı taraf uyluğunu da steril hazırlayıp önce oturur pozisyonda artroskopiye başlamaktayız. Fasya lata greftinin alınması için daha az invaziv yöntemler de tarif edilmesine karşılık standart fasya lata grefti şu şekilde alınmaktadır. Lateral femoral epikondilin $15 \mathrm{~cm}$ proksimalinden trokanter majörün $10 \mathrm{~cm}$ distaline kadar uzanan ve uyluğu tam ortalayan $15 \mathrm{~cm}$ uzunluğunda uzunlamasına bir lateral cilt kesisi uygulanır (Şekil 1). İnsizyon sonrası cilt altı alınacak greftin boyutu kadar dekole edilmelidir. Bundan daha fazla uygulanacak dekole etme işlemi, ameliyat sonrası bu bölgede ölü boşluk oluşumuna yol açarak seroma formasyonu gelişim riskini artıır. Yaklaşık $20 \times 5 \mathrm{~cm}$ boyutunda tam kat fasya lata grefti çıkarılır ve greft masaya alınır. Cilt altı ölü boşluk bırakılmayacak şekilde kapatıldıktan sonra cilt kapatıır. Greft alındıktan sonra fasya defektinin uç uca

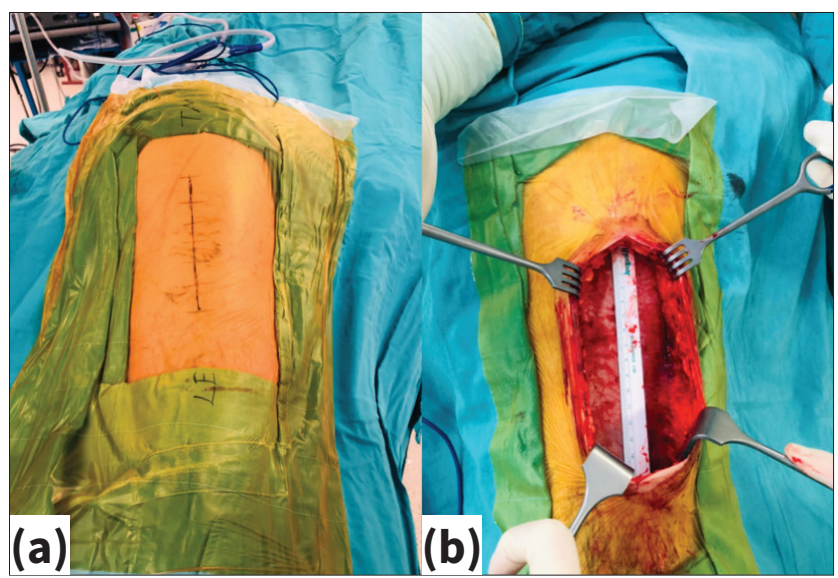

Şekil 1.a,b. Fasya lata greftinin alınması için uygulanan lateral uyluk insizyonu (a) ve greft alınmadan önce ölçüm yapılışı (b). kapatılmasına gerek yoktur. Fasyanın bu şeklide gergin bir şekilde kapatılması ameliyat sonrası gerginlik ve sonucunda ağrıya sebep olabilir. Etkili bir kanama kontrolü ve greft alınan sahaya hemovak dren yerleştirilmesi ameliyat sonrası seroma gelişim riskini azaltacaktır.

Cilt kapatıldıktan sonra ameliyata yan yatar pozisyonda devam edilecekse greft bir asistan tarafından steril masada hazırlanabilir. Bunun aksine ameliyata oturur poziyonda devam edilecekse hastanın örtüleri açılarak ameliyat ekibi tarafından hasta oturur pozisyona getirilip omuz bölgesi steril hazırlanır ve hasta tekrar örtülür. $\mathrm{Bu}$ esnada greft cerrah tarafından hazırlanabilir. Greft alındıktan sonra steril masa da hazırlanır. Greftin iç ve dış yüzeyindeki yumuşak dokular temizlenir. Greft uzunlamasına, ortalama dört kat katlanarak yaklaşık $4 \times 5 \mathrm{~cm}$ boyutuna getirilir. Yöntemi geliştiren araştırmacı Mihata, SKR yöntemi için hazırlanan fasya lata greftlerinin ideal olarak 6-8 mm kalınlıkta olması gerektiğini bildirmiştir. ${ }^{[10]}$ Yine buna paralel olarak farklı araştırmacılar daha kalın greft kullanılan hastalarda daha iyi klinik sonuçların elde edildiğini bildirmişlerdir. ${ }^{[11]} \mathrm{Bu}$ bilgiler ışığında mümkün olduğunca ortalama 6-8 mm greft kalınlığı elde edilmeye çalışıımalıdır. Greft katlanıp yeterli kalınlık elde edildikten sonra emilebilir ipler ile çevresel dikişler atılarak greft tek parça haline getirilir (Şekil 2).

Greft hazırlığı tamamlandıktan sonra standart posterior portal açılarak omuz artroskopisine başlanır. Kamera görüntüsü altında rotator interval seviyesinde anterior portal açılır. Bu iki portal kullanılarak eklem içi değerlendirme ve gerekli eklem içi işlemler tamamlanır. Onarılamaz düzeyde rotator manşet yırtığı olan hastaların sıklıkla biseps tendon bozuklukları da görülmektedir. Kliniğimizde bu hastalarda biseps tendon problemleri- 


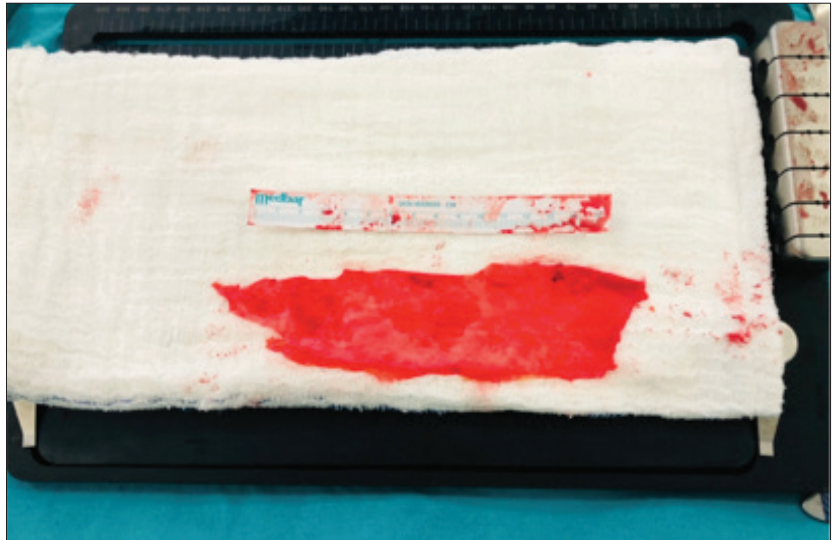

(a)

\section{(b)}

Şekil 2.a,b. Fasya lata greftinin yumuşak dokular temizlendikten sonraki durumu (a). Greftin uygun kalınlık ve ölçülere getirildikten ve çevresel dikişler ile sağlamlaştırıldıktan sonraki görünümü (b). nin tedavisi için tercih ettiğimiz yöntem büyük oranda tenotomidir. Superior kapsüler rekonstrüksiyon yöntemi uzun süren bir cerrahi işlem olduğu için tenotomi bu hasta grubunda hızlı ve düşük komplikasyonlu bir tedavi seçeneği sunmaktadır. Eklem içi işlemler tamamlandıktan sonra kamera posterior portalden çıkarılıp aynı portalden subakromiyal boşluğa yönlendirilir. Bu aşamada rotator manşetin mobilitesi ve buna göre primer onarım uygulanıp uygulanamayacağı değerlendirilir (Şekil 3). Sonrasında lateral portal açılır. Lateral portalin bir damar yolu iğnesi aracılığıyla kamera görüntülemesi altında ve glenoidin üst kısmına dik olarak ulaşabilecek şekilde açılması cerrahi esnasında kolaylık sağlar (Şekil 3).

Rotator manşetin primer onarıma uygun olmadığı netleştirildikten sonra olağan akromioplasti uygulanır. Mihata ve ark., 2016 yılında yayımladıkları biyomekanik çalışmada, SKR esnasında akromiyoplasti uygulanılmasının subakromiyal temas basıncını azalttığını ve pürüzsüz bir akromial yüzeyin greft sağ kalımına katkı sağlayabileceğini bildirmişlerdir. ${ }^{[12]}$ Buna ek olarak akromiyoplasti uygulanması, subakromiyal hacmi genişleterek cerrahi esnasındaki çalışma alanının artmasını sağlar. Akromiyoplasti tamamlandıktan sonra glenoid tarafın hazırlığına başlanır. Supraspinatus tendonu glenoid superior kenarının $5 \mathrm{~mm}$ mediyaline kadar rezeke edilmelidir. Infraspinatus tendonu rekonstrüksiyon sonrası grefte tespit edileceği için rezeke edilmemeli ve korunmalıdır. Supraspinatus uygun şekilde rezeke edildikten sonra glenoid superior yüzeyinin greft inkorporasyonunu sağlamak için kanayan bir kemik yatağı elde edilene kadar yumuşak dokularının eksize edilmesi ve dekortike edilmesi gerekir (Şekil 4).

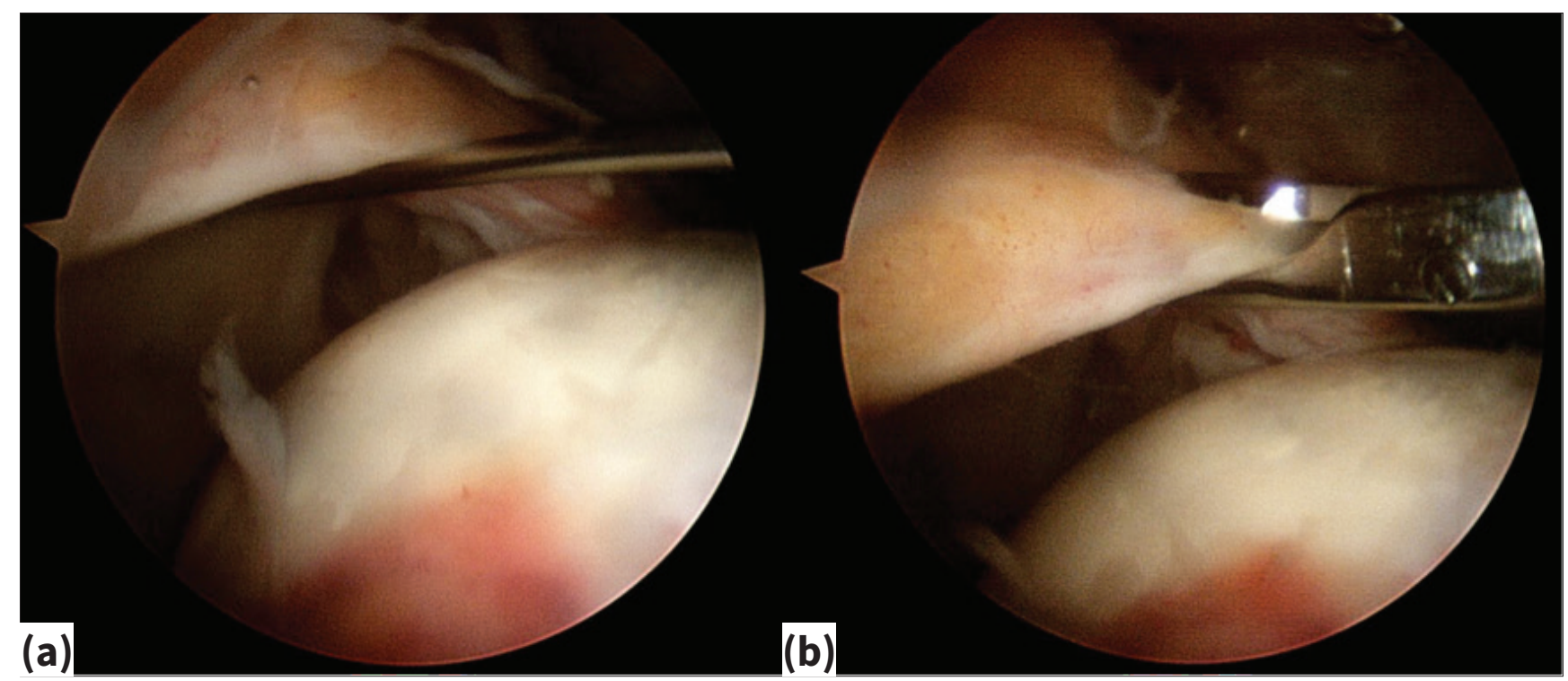

Şekil 3.a,b. Posterior portalden görüntüleme esnasında lateral portalin damar yolu iğnesi yardımıyla yerinin belirlenmesi; bu teknik ile glenoid üst kısmına rahat ulaşıır ve lateral portalin bu bölgeye dik bir şekilde açılması cerrahi esnasında kolaylık sağlar (a). Portal açıldıktan sonra rotator manşet mobilitesinin ve doku kalitesinin değerlendirilmesi (b). Rotator manşetin doku kalitesi kötü ise ve gerekli gevşetmelerden sonra anatomik ayak izine gerilimsiz olarak getirilemiyorsa SKR endikasyonu kesinleştirilmiş olur 


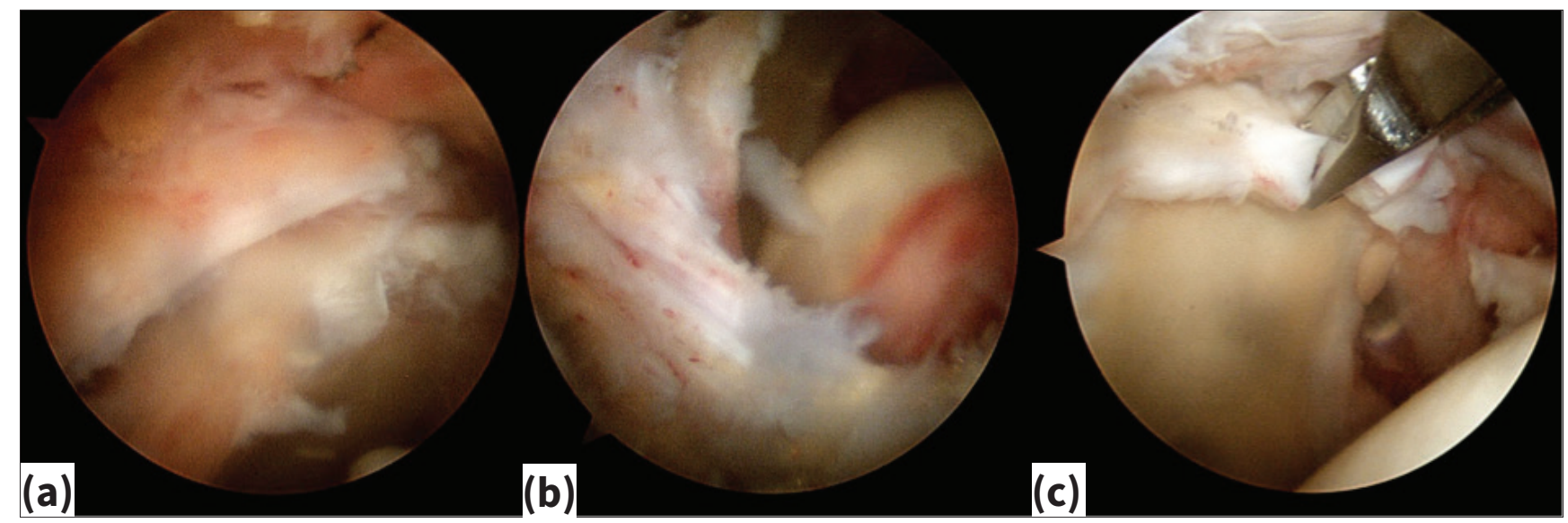

Şekil 4.a-c. Supraspinatus tendonunun glenoid superior kenarından $5 \mathrm{~mm}$ mediyale kadar rezeke edilmiş hâli (a), rezeke edilmeden korunmuş infraspinatus tendonunun görüntüsü (b) ve superior labrumun rezeksiyonu (c) gösterilmektedir.

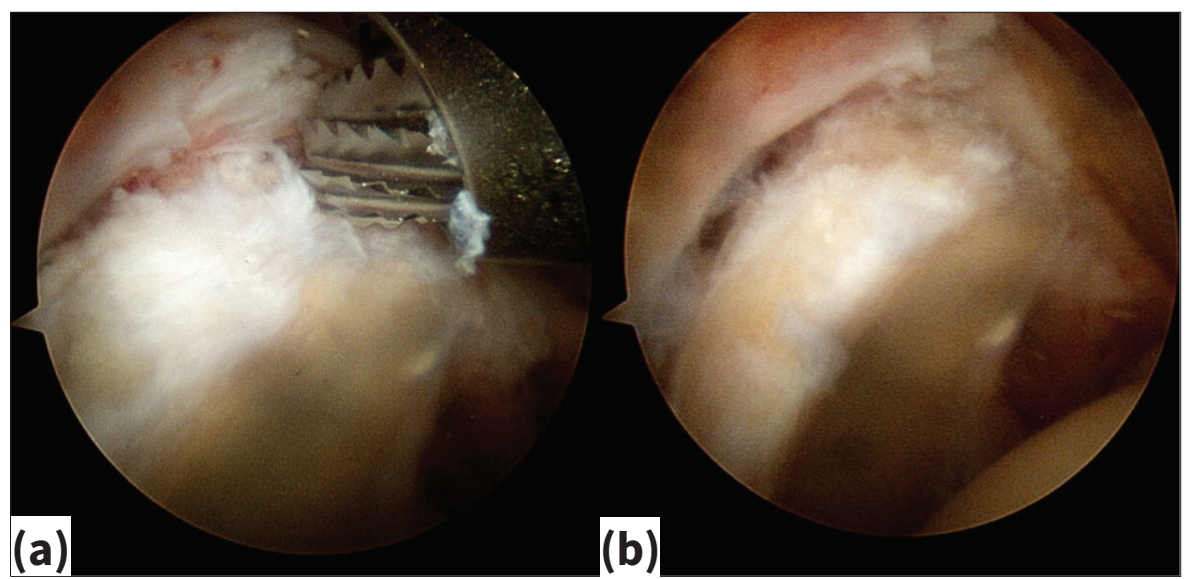

Şekil 5.a,b. Glenoid superior yüzeyin yüksek hızlı artroskopik traşlayıcı uç ile dekortike edilmesi (a). Dekortikasyon tamamlandıktan sonraki glenoid superior yüzeyin son halinin görünümü (b).

Glenoid superior labrum artroskopik el aletleri yardımı ile rezeke edilir. Bu bölgede yumuşak dokular çok sert olduğu için alternatif olarak radyofrekans kullanılabilir. Ancak bu yapılırken çok fazla mediyale yönlenmemeye çalışılmalıdır. Aşırı radyofrekans kullanılması spinoglenoid boşluktan geçen supraskapuler sinire termal hasar vererek daha sonradan rekonstrüksiyona dâhil edilecek olan infraspinatus denervasyonuna sebep olabilir. Superior labrum rezeke edildikten sonra yüksek hızlı traşlayıcı artroskopik uç kullanılarak glenoidin superioru dekortike edilir. Bu uygulanırken özellikle kemik çapası yerleştirilecek olan glenoid anterior ve posterior bölgedeki subkondral kemik tespit gücünü bozmamak adına korunmalıdır (Şekil 5).

Glenoid hazırlığından sonra greftin humeral tarafta tespit edileceği tüberkulum majus dekortike edilerek hazırlanır. Bu işlem uygulanırken yine anterior ve posterior humeral kemik çapalarının yerleştirileceği bölgelerdeki subkondral kemik tespit gücünü bozmamak adına korunmalıdır (Şekil 6).
Glenoid ve humeral taraftaki greft yerleşim sahaları hazırlandıktan sonra tespit aşamasına geçilir. Bir artroskopik cetvel yardımıyla glenoid kenarı ile tüberkulum majusun en lateral kısmı arasındaki mesafe ölçülerek greft boyutu hesaplanır. Glenoid taraftaki tespit için bu mesafeye yaklaşık $5 \mathrm{~mm}$ eklenmelidir. Greft buna göre uygun boyuta getirilir. Daha önceden açılmış olan anterior portal kullanılarak glenoid antero-superior kenarına bir adet 3,5 $\mathrm{mm}$ titanyum kemik çapası yerleştirilir. Kemik çapanın kıkırdak sınııından yaklaşık $5 \mathrm{~mm}$ mediyale yerleştirilmesi gerekir (Şekil 7). Biz kliniğimizde rutin olarak çift iple yüklenmiş kemik çapalarını tercih ediyoruz. ilk kemik çapası yerleştirildikten sonra buna ait ipler anterior portalde bırakılır. Ardından glenoid postero-superior kemik çapası yerleştirilir (Şekil 7). Biz bu kemik çapasını genellikle Nevasier portalinden yerleştirmekte ve ipleri bu portalde bırakmaktayız. Alternatif olarak bu kemik çapası küçük bir posterolateral portalden de yerleştirilebilir. Ancak tüm operasyon posterior portalden görüntülenerek uygulandığı için posterolateral portaldeki ipler görüntülemeyi 


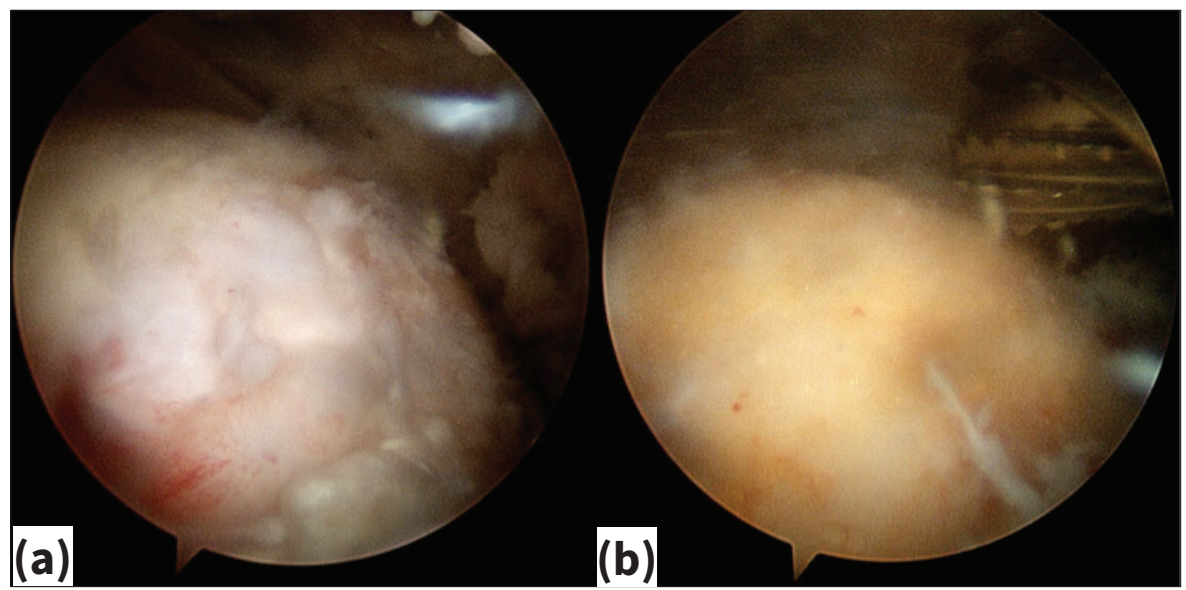

Şekil 6.a,b. Humeral tarafta greftin yerleştirileceği tüberkulum majusun dekortikasyon öncesi (a) ve sonrası (b) görünümleri.

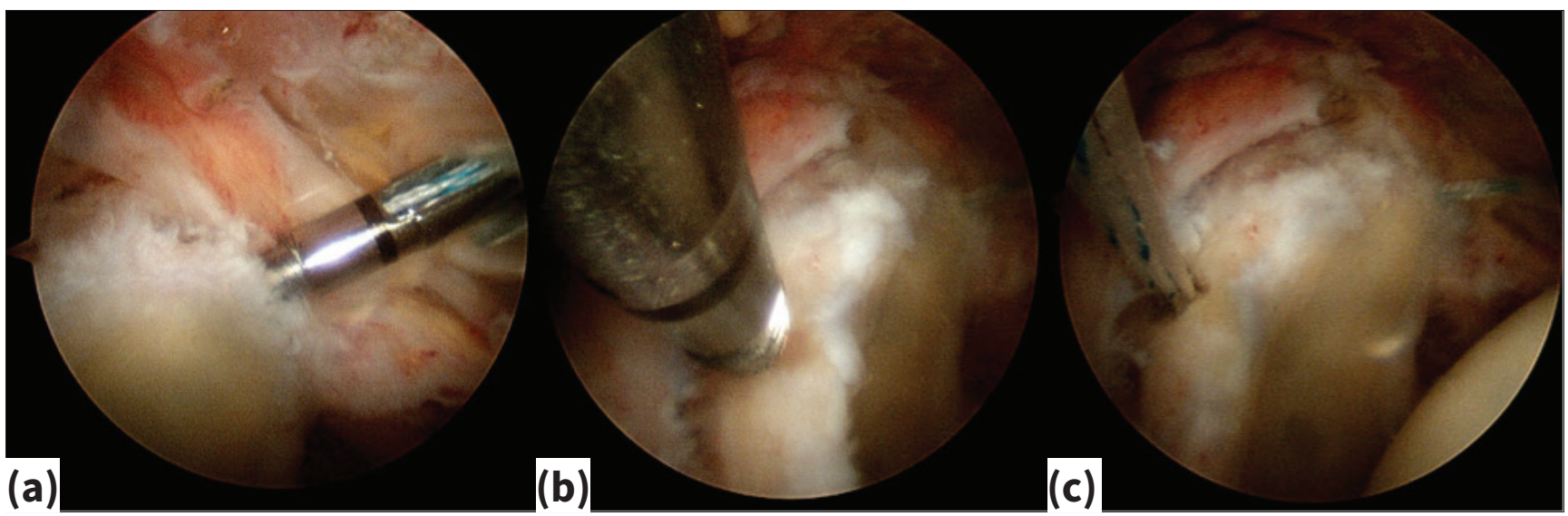

Şekil 7.a-c. Antero-superior glenoid kemik çapasının anterior portalden yerleştirilmesi (a). Postero-superior kemik çapasının Nevasier portalinden yerleştirilmesi (b). Glenoid kemik çapalarının yerleştirilmelerinden sonraki görüntü (c).

engelleyebilmektedir. Özellikle postero-superior glenoid kemik çapası yerleştirilirken eklem kıkırdağına girmemeye özen gösterilmelidir.

Glenoid taraf tamamlandıktan sonra humeral tarafa geçilir. illk olarak anterior kemik çapası yerleştirilir (Şekil 8). Humeral tarafta biz rutin olarak $5,5 \mathrm{~mm}$ çift ip yüklü titanyum kemik çapaları kullanmaktayız. Anterior kemik çapası rotator manşetin ayak izine uygun olacak şekilde kıkırdak sonlanmasının hemen lateraline yerleştirilmelidir. Posterior humeral kemik çapası ise çıplak alan (bare area) boş bırakılacak şekilde kıkırdak bitiminden yaklaşık $7 \mathrm{~mm}$ laterale yerleştirilmelidir (Şekil 8). Bu şekilde uygulandığında rotator manşet ayak izi anatomik olarak tekrar oluşturulmuş olur.

Tüm kemik çapaları yerleştirildikten sonra greft transferi aşamasına geçilir. Glenoid çapalarındaki iplerin bacakları lateral portale alınır. Bu işlem uygulanırken anterior çapadan gelen iplerin anteriorda, posterior çapadan gelen iplerin posteriorda steril örtülere tutturulması bu çapa- ra ait iplerin çaprazlanmasını önler (Şekil 9). Alternatif olarak glenoid çapalarından gelen iplerin greft transferi aşamasında grefti çekecek olan bacakları anterior portal ve Nevasier portalinde bırakılabilir. Bu teknik ile iplerin birbirine dolanma riski azalmasına rağmen, greft yerleşimi sonrası subakromiyal alan greft tarafından doldurulacağı için glenoid tarafta iplerin bulunmasında zorluklar yaşanabilmektedir.

İpler lateral portale taşındıktan sonra, bu portalin greft geçişine izin verecek şekilde büyütülmesi gerekmektedir. Greft geçişi için portalin genellikle işaret parmağının geçeceği kadar büyütülmesi yeterli olmaktadır. Bu aşamadan sonra daha önceden hazırlanmış olan fasya lata grefti cerrahi sahaya getirilir. Greftin glenoid tarafına yerleştirilecek olan kısmından, glenoid çapalarına ait iplerin birer bacağı geçirilir (Şekil 10). İplerin grefti yırtmaması için greft mediyal kenarının $5 \mathrm{~mm}$ lateralinden ve birkaç kez geçilmesi gerekmektedir. Ayrıca anterior ve posterior glenoid çapalara ait ipler greftten geçilirken kemik çapaları arasındaki 


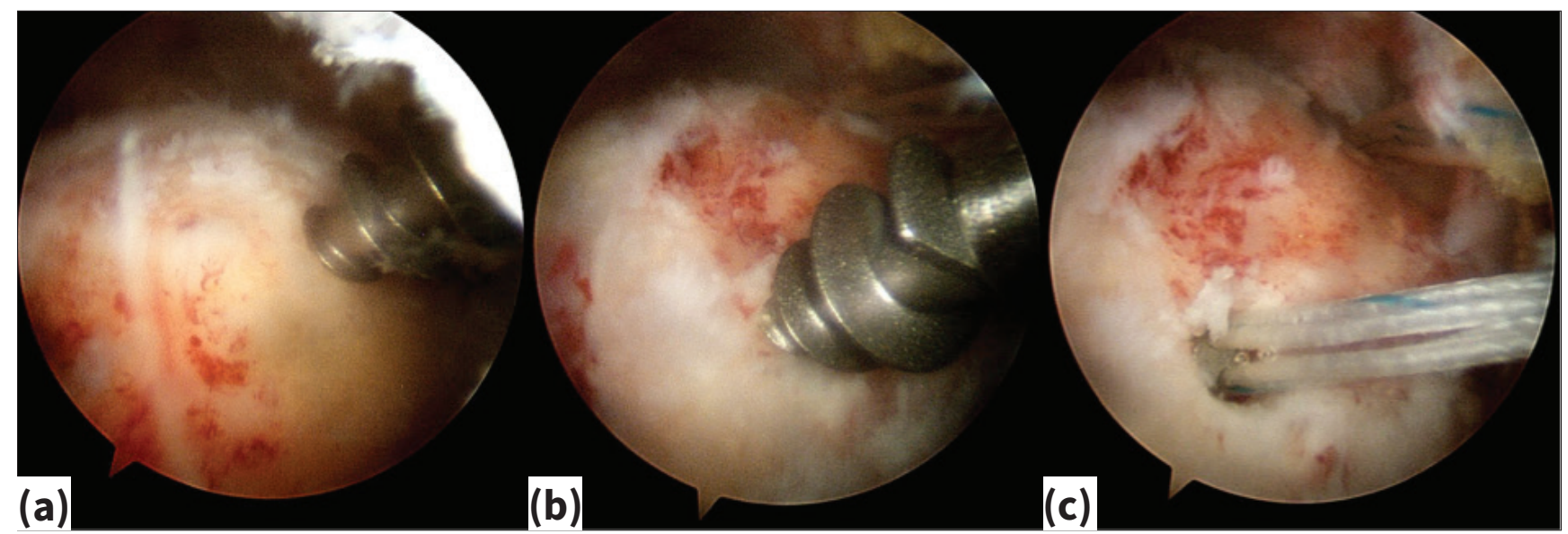

Şekil 8.a-c. Anterior humeral kemik çapasının (a) ve posterior humeral kemik çapasının yerleştirilmesi (b). Humeral kemik çapalarının yerleştirilmelerinden sonraki görüntü (c).

mesafe kadar aralıkla greftten geçilmelidir. İpler greftten geçildikten sonra kendi üzerlerinde kilitlenirler. İplerin kilitlenmesi, grefti asılacak iplerin çekmesi esnasında, greft üzerindeki iplerin sıyrılmasını önler. Glenoid taraftaki ipler greftten geçildikten sonra humeral taraftaki iplerin her iki bacağı da horizontal mattress şeklinde greftin lateral kenarından geçilir. Humeral çapalara ait ipler geçilirken glenoid ve tüberkulum majus arasındaki mesafe hesaba katılarak greft içinden geçilmelidir. Humeral çapalara ait iplerin kendi üzerinde kilitlenmemesi gerekmektedir (Şekil 10).

Tüm ipler greftten geçirildikten sonra greft üzerindeki ipler klempler ile tutturularak işaretlenir. Greft geçişini kolaylaştırmak için ipler içeride olacak şekilde greft ikiye katlanır (Şekil 11). Kamera görüntüsü altında glenoid kemik çapalarına ait greftten geçirilmeyen ipler yavaşça çekilerek greft asansör yöntemiyle subakromiyal aralığa yönlendirilir. Greft transferi aşamasında cerrah parmağı ile grefti arkadan destekler ve greft geçişine yardımcı olur (Şekil 11). Kamera görüntüsü altında greftin glenoid tarafa tamamen oturduğudan emin olunmalıdır. Glenoid tarafta greft yerleştirildikten sonra cerrah lateral portalden parmağını subakromiyal alana sokarak greftin humeral tarafa oturmasına yardımcı olur.

Greft glenoid ve humeral tarafa tamamen oturtulduktan sonra glenoid taraftaki asansör görevi gören ipler cerrahi asistan tarafından gergin tutulurken, diğer glenoid

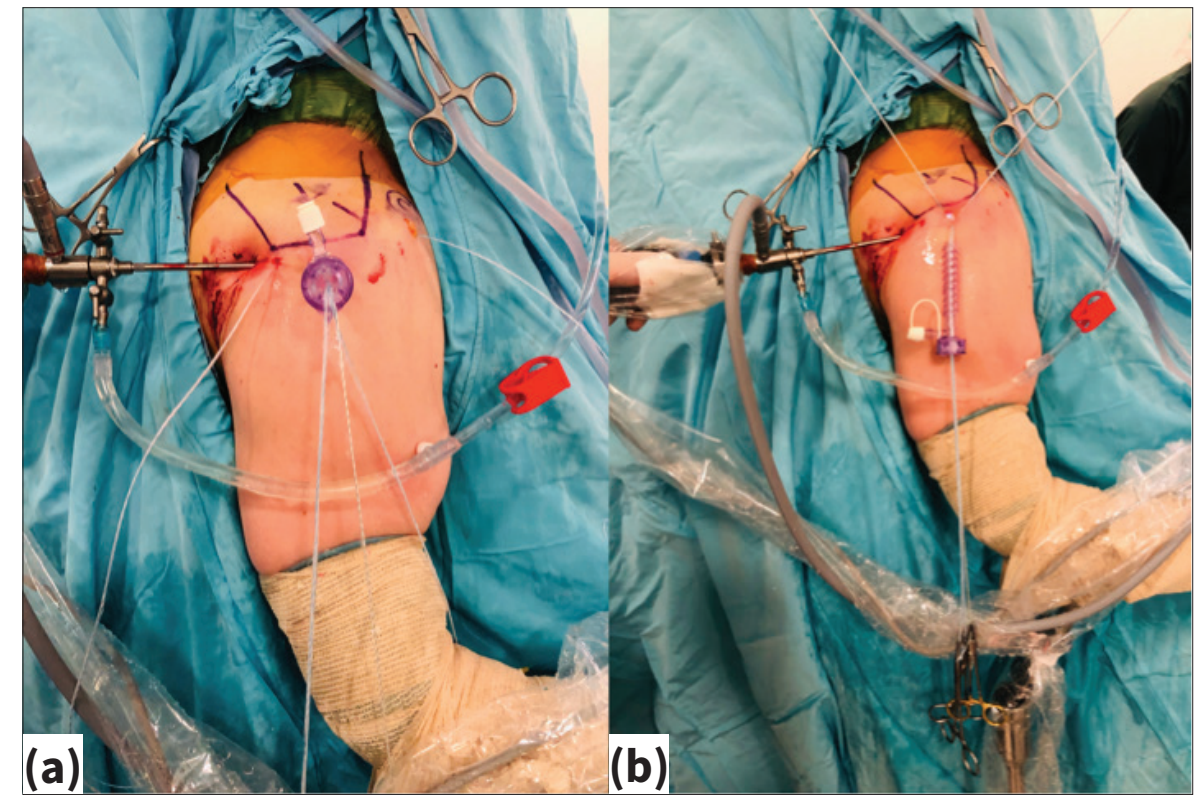

Şekil 9.a,b. Glenoid ve humeral kemik çapalarının yerleştirilmelerinden sonra iplerin klinik görüntüsü (a). Glenoid kemik çapalarına ait iplerin lateral portale taşındıktan sonrasına ait görüntü (b). 


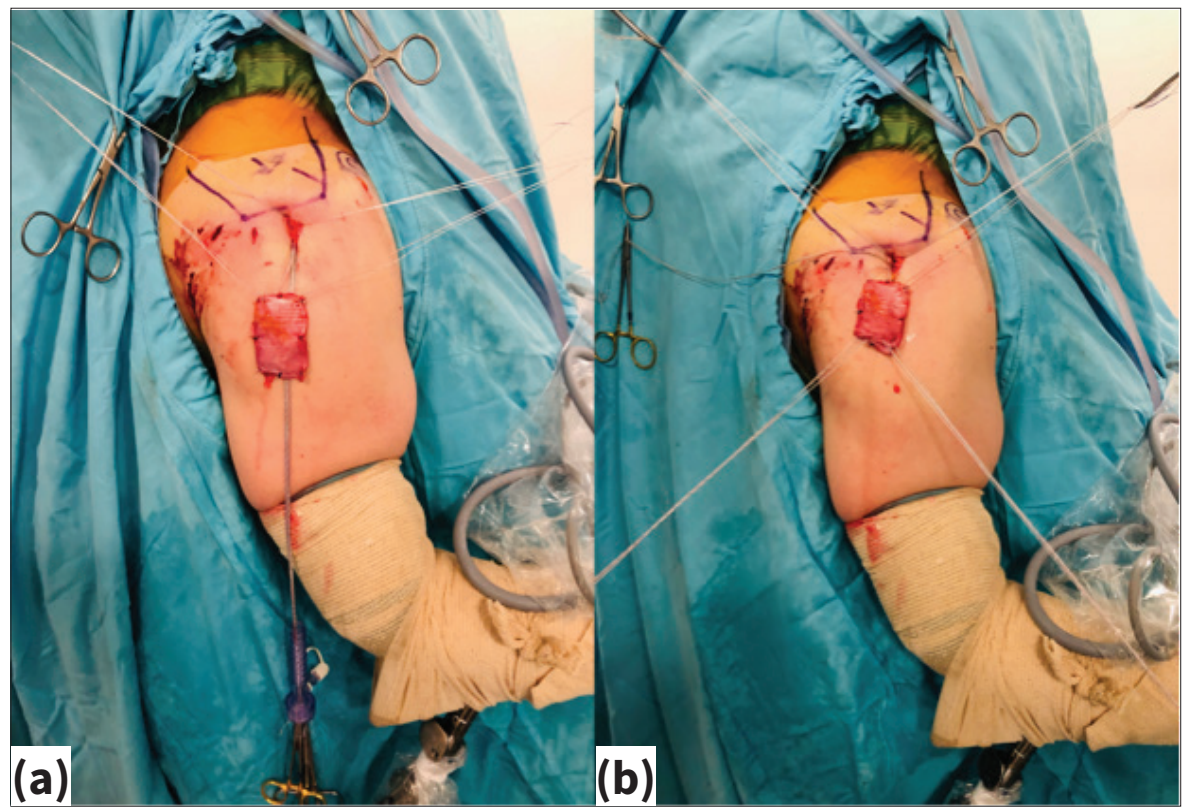

Şekil 10.a,b. Glenoid kemik çapalarına ait iplerin birer bacaklarının greftten geçirilmesi sonrası (a) ve humeral kemik çapalarının greftten geçirildikten sonraki (b) klinik görüntüler.

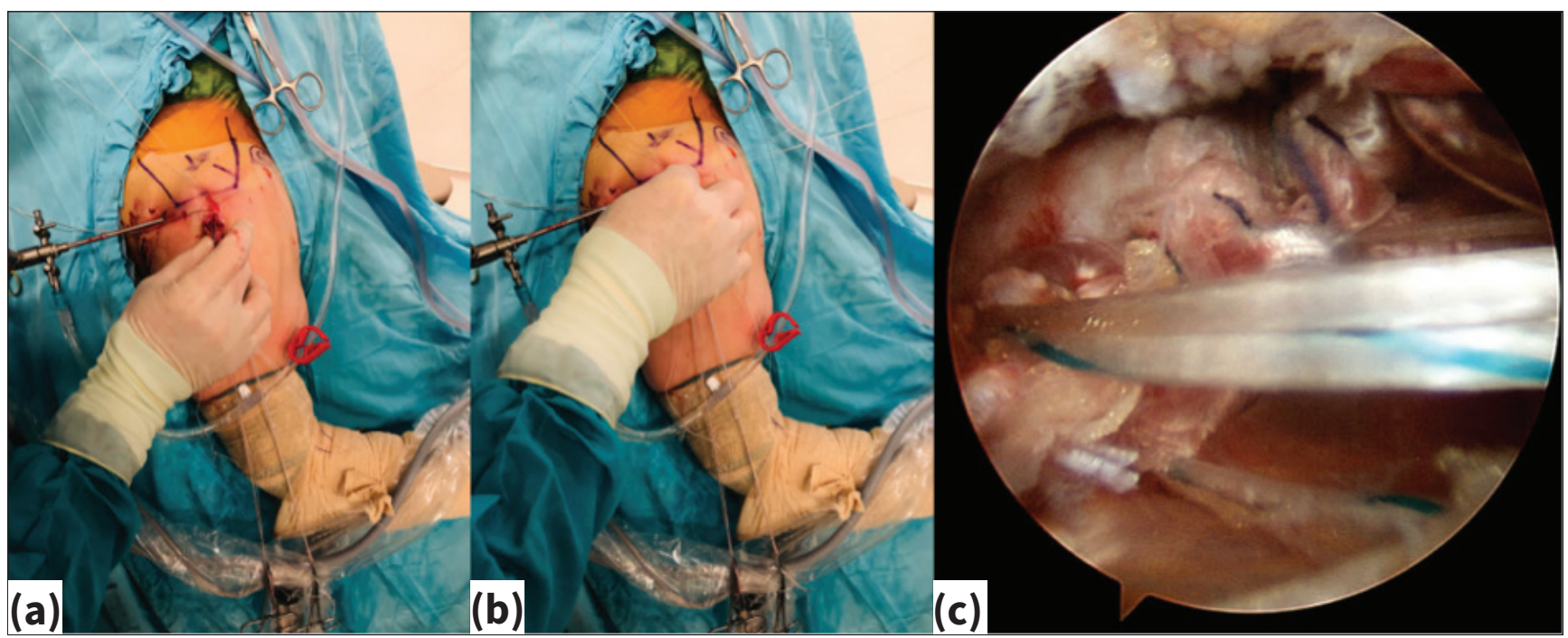

Şekil 11.a-c. Glenoid taraftaki çapaların asansör görevi gören bacaklarının çekilmesi ve ikiye katlanmış greft içindeki ipler (a). Greftin transferi esnasında cerrahın parmağı ile greftin geçişine yardım etmesi (b). Greftin glenoid üst yüzeyine oturmuş görüntüsü (c).

ipleri artroskopik düğüm atıcı yardımıyla bağlanır. Düğüm atmadan önce her ipin başka bir ip ile dolaşmadığı kontrol edilmelidir. Düğüm atma esnasında asansör görevi gören ipler sabit bacak olarak seçilmeli ve düğüm atarken sürekli gergin tutulmalıdır. Bu sayede greft ve kemik arasında boşluk oluşmaz ve iyi düzeyde kemik-greft teması sağlanır. Glenoid kemik çapalarının greft üzerindeki iplerinin daha önceden kilitlenmiş olması sebebiyle kayan dügüm atma imkânı yoktur. Bu nedenle glenoid taraftaki dügüumlerin tek tek atılması gerekmektedir. Glenoid taraftaki iplerin hepsi bağlandıktan sonra humeral tarafta greft tespiti ve greft gerginliğinin ayarlanması aşamasına gelinir. Kol nötral rotasyon, $10^{\circ}$ anterior elevasyon ve $30^{\circ}$ abduksiyon pozisyonuna alınır. Bu pozisyonda humeral taraftaki ipler dügümlenir ancak çift sıra onarım amacıyla ipler kesilmez. Yine aynı pozisyonda bu ipler birbiriyle çaprazlanarak iki adet çakılabilir kemik çapası yardımıyla ikinci sıra onarım tamamlanır (Şekil 12). 


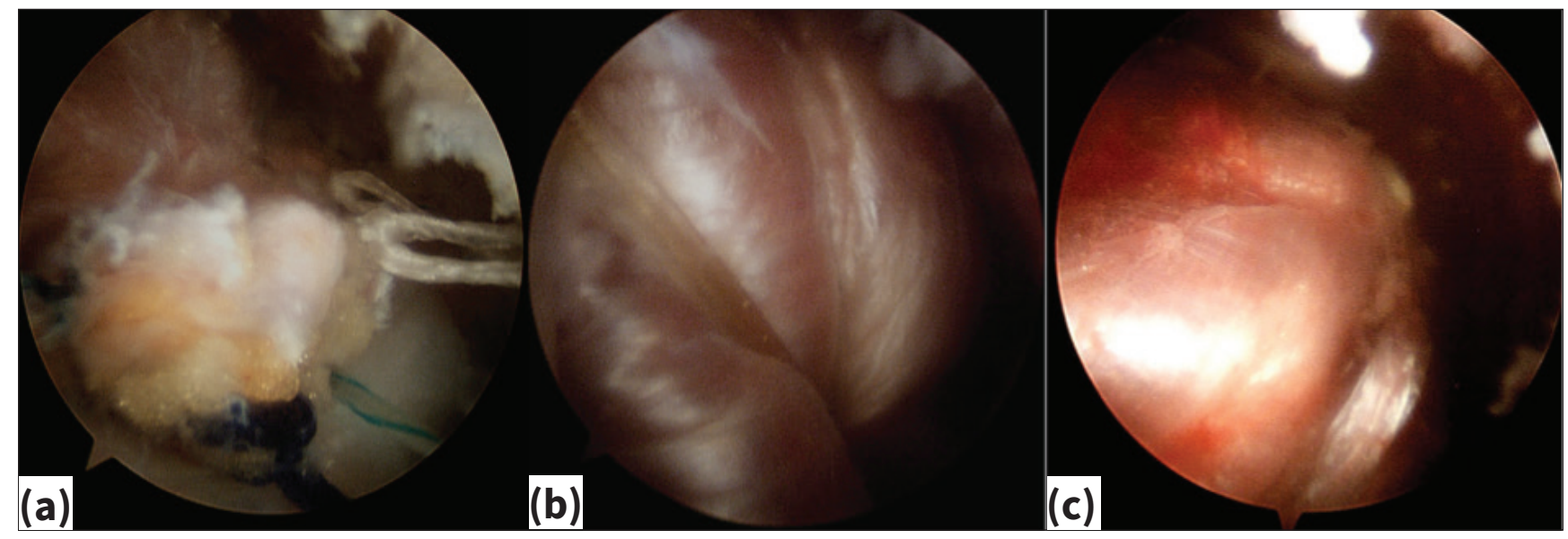

Şekil 12.a-c. Greftin humeral tarafından geçilen mediyal sıra kemik çapalarına ait sütürlerin düğümlenmiş hali (a). Aynı kemik çapalarına ait iplerin lateral sırayı oluşturmak üzere düğümsüz çakılabilir kemik çapalar ile tespiti sonrası artroskopik görüntüleri (b,c).

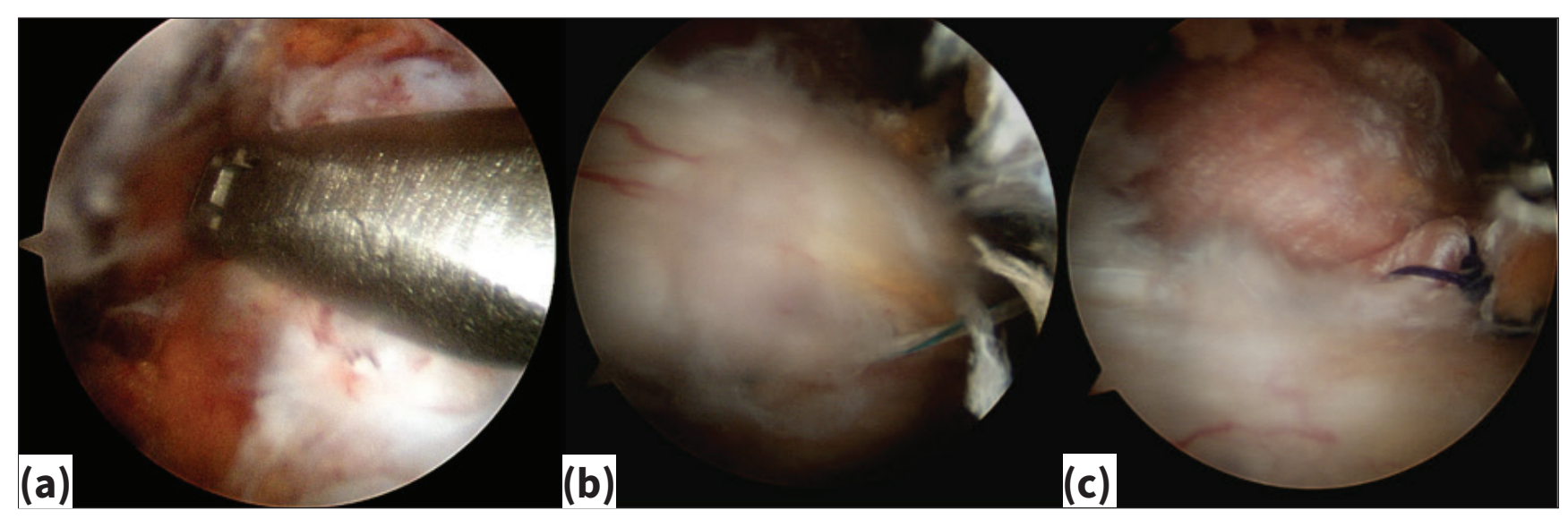

Şekil 13.a-c. İnfraspinatus tendonundan serbest iplerin geçirilme aşaması (a) ve ip geçirildikten sonraki görüntü (b). İnfraspinatus tendonunun rekonstrüksiyona dáhil edilmesi ve tespiti sonrası artroskopik görüntü (c).

Fasya lata greftinin tespiti sonrası daha önceden korunan infraspinatus tendonunun rekonstrüksiyona dâhil edilmesi gerekmektedir. Mihata ve ark. yayınladıkları biyomekanik çalışmada, infraspinatus dâhil edildiği zaman SKR'nin humerus başının yukarıya translasyonunu daha etkili olarak önlediğini bildirmişlerdir. ${ }^{[13]}$ Sütür geçiriciler kullanılarak infraspinatus tendonu ve fasya lata greftinin posterior kenarından serbest güçlendirilmiş ipler geçirilir ve bu ipler bağlanarak infraspinatus tendonu rekontrüksiyona dâhil edilmiş olur (Şekil 13).

\section{AMELIYAT SONRASI REHABILITASYON}

Superior kapsül rekonstrüksiyonu, göreceli olarak yeni bir cerrahi yöntem olduğu için ameliyat sonrası rehabilitasyon açısından kanıt düzeyi yüksek olan çalışmalar kısıtlı sayıdadır. ${ }^{[14]}$ Bununla birlikte genel olarak önerilen rehabilitasyon protokolü masif rotator manşet yırtıklarının primer onarımı sonrası uygulanan rehabilitasyon ile benzerlik göstermektedir. Farklı çalışmalarda abduksiyon destekli kol askısı kullanımı 3-6 hafta, pasif hareketlere başlanması 2-6 hafta, aktif omuz hareketlerine başlanılması 4-8 hafta, tam aktiviteye dönüş ve güçlendirme safhaları ise 12-52 hafta arasında değişmektedir. ${ }^{[14]}$ Ameliyat sonrası rehabilitasyonun her hastaya özgü ayarlanması, hastanın greft ve kemik kalitesi, tespit gücü, yaş ve aktivite düzeyine göre bir rehabilitasyon programı belirlenmesi, greft yetmezliği gibi komplikasyonların önüne geçmek için faydalı olacaktır (Şekil 14 ve 15).

\section{TARTIŞMA}

Onarılamaz düzeydeki rotator manşet yırtıkları için farklı tedavi seçenekleri bulunmasına rağmen bu seçeneklerin hemen hepsinin kendine has kısıtlılıkları bulunmaktadır. Bu kısıtlılıkların önüne geçmek için Dr. Mihata tarafından geliştirilen ve göreceli olarak yeni bir yöntem olan superior kapsül rekonstrüksiyonunun tanımlanmasından 


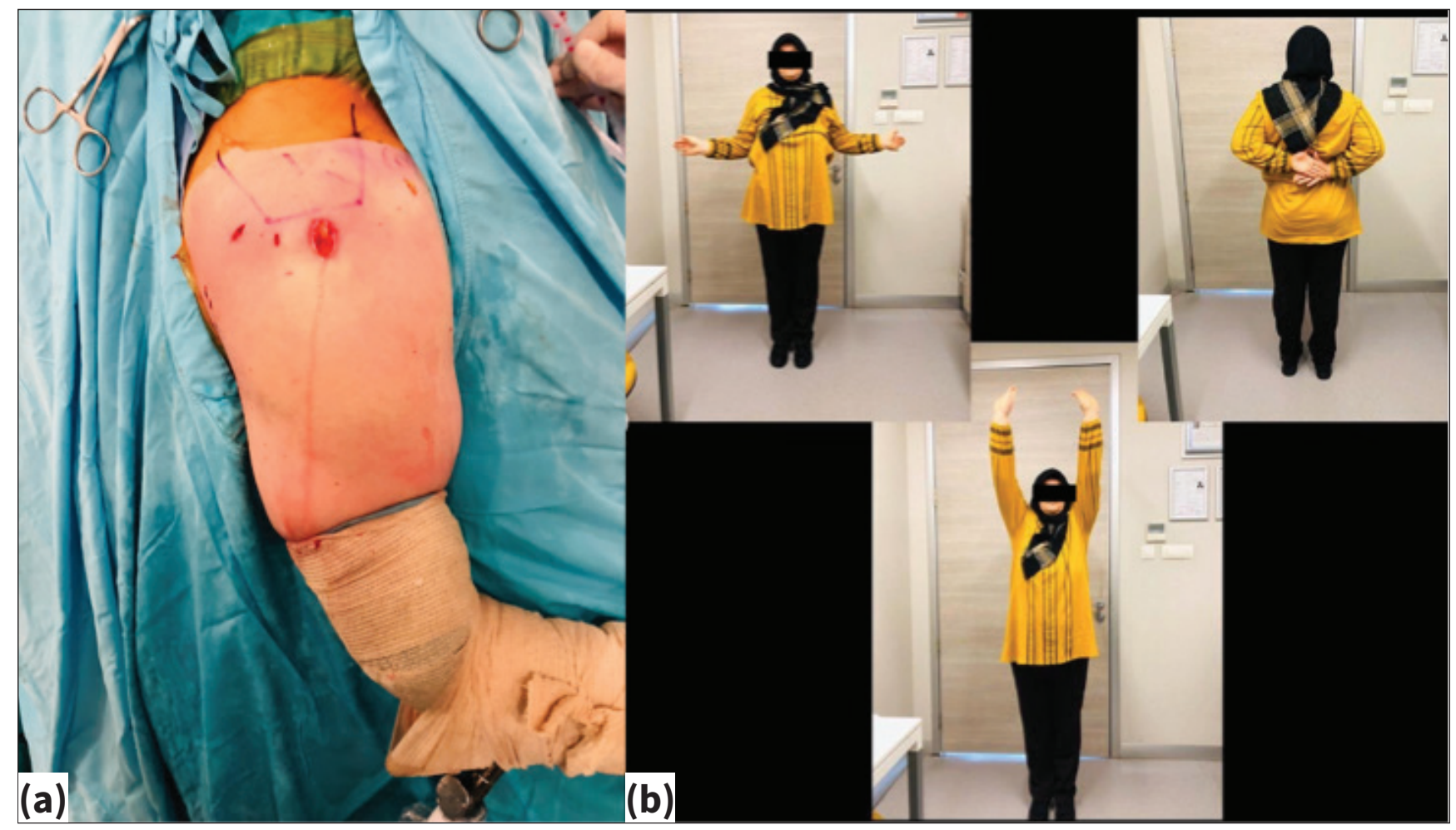

Şekil 14.a,b. İşlem bittikten sonra cerrahi sahanın klinik görüntüsü (a). Aynı hastaya ait cerrahi sonrası üçüncü aydaki klinik sonuçların görüntüleri (b).
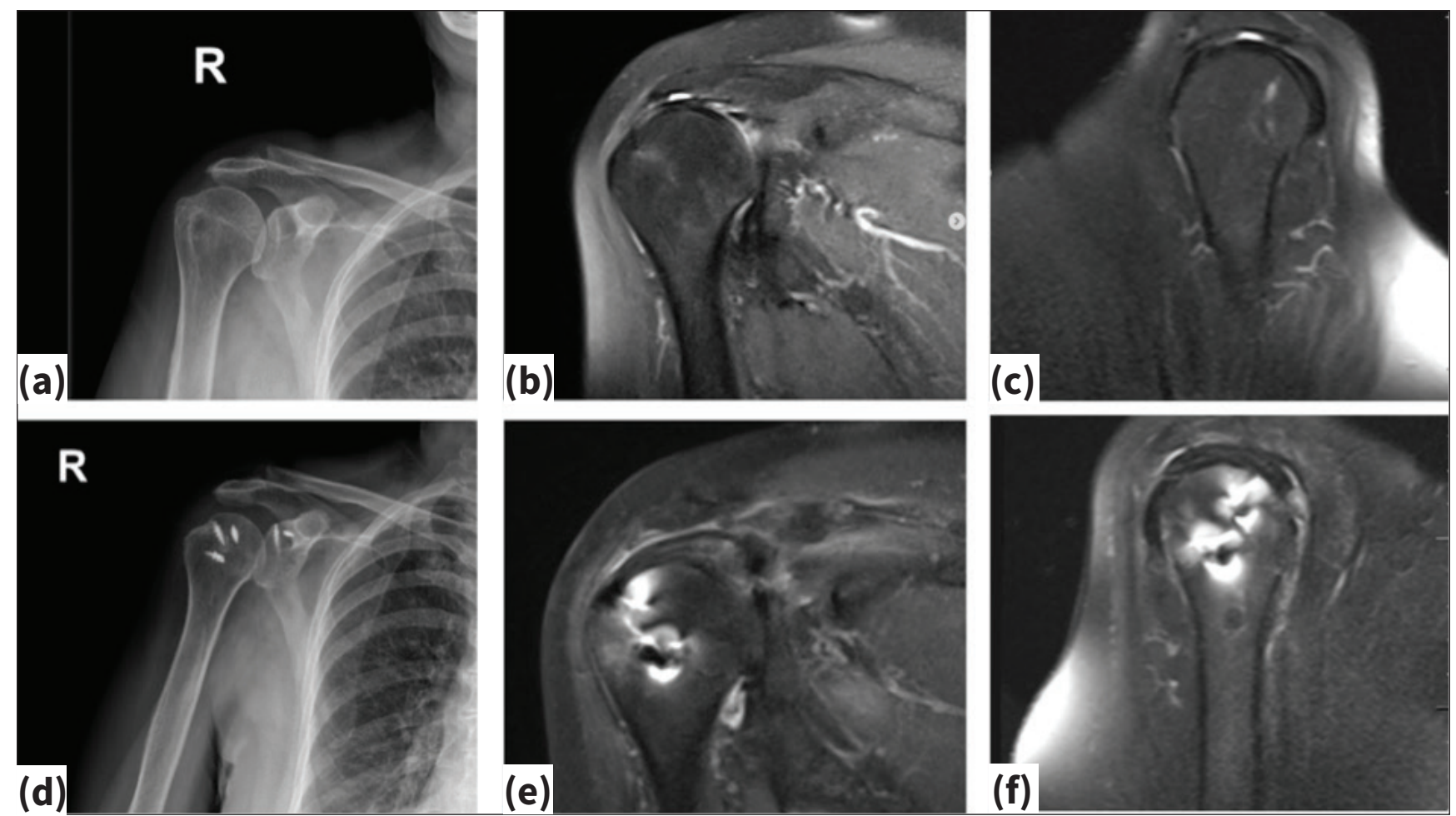

Şekil 15.a-f. SKR uygulanan hastanın sırasıyla; ameliyat öncesi grafi görüntüsü (a), koronal (b) ve sagital (c) MR kesitleri. Ameliyat sonrası bu görüntülerdeki değişiklikler; grafi (d), koronal (e) ve sagital (f) MR kesitlerine ait görüntüler. 
sonra birçok farklı çalışmada tatminkâr ve başarılı sonuçlar bildirilmiştir. Mihata ve ark., bu konu hakkında yayımladıkları ilk klinik çalışmada 23 hastayı ortalama 34,1 ay takip etmişler ve ameliyat öncesi ortalama $84^{\circ}$ olan öne omuz elevasyonunun ameliyat sonrası ortalama $148^{\circ}$ 'ye, dış rotasyonun $28^{\circ}$ 'den $40^{\circ}$ 'ye, ASES (American Shoulder and Elbow Surgeons) skorunun ise 23,5'ten 92,9 puana yükseldiğini bildirmişlerdir. ${ }^{[7]}$ Takip süresince çekilen MR sonuçlarına göre hastaların \%83'ünde greft ve infraspinatus tendonunun devamlılığının devam ettiği gözlenmiştir. Üç hastada infraspinatus yırtığı, bir hastada greft yetmezliği izlenmiştir. ${ }^{[7]} 2018$ yılında yine Mihata ve ark., SKR'ye ait beş yıllık takiplerini yayınlamıştır. ${ }^{[15]} \mathrm{Bu}$ çalışmada beşinci yılda ASES skorunun birinci yıl sonundakine göre arttığı, birinci yıldaki ameliyat öncesine göre ortalama $53^{\circ}$ artan öne elevasyonun ise beşinci yılda ameliyat öncesine göre $66^{\circ}$ arttığı bildirilmiştir. Beş yıl sonunda hastaların $\% 10$ 'unda greft yetmezliği ve ileri düzeyde rotator manşet artropatisi izlenmiştir. Mihata ve ark. yayınladıkları çalışmalar ışığında aynı yöntemi uygulayan farklı araştırmacılar da benzer şekilde kabul edilebilir düzeyde iyi sonuçlar bildirmiştir. ${ }^{[16-21]}$

Başarılı klinik sonuçlarına rağmen her cerrahi yöntemde olduğu gibi SKR'de de bazı komplikasyonlar yaşanmaktadır. 2020 yılında Altıntaş ve ark.'nın yayınladıkları sistematik derlemede farklı çalışmalardaki 338 hastanın \%19'unda komplikasyon bildirilmiştir. Bu hasta grubunda greft yetmezliği \%13 görülme oranıyla en sık karşılaşılan komplikasyondur. Komplikayonlar arasında greft yetmezliğinin öne çıkması araştırmacıları greft tipi ve greft kalınlığı gibi tartışmalı konulara yönlendirmiştir. ${ }^{[22]}$ Superior kapsüler rekonstrüksiyon yöntemini tarif eden Mihata, bütün cerrahilerinde fasya lata grefti kullanmıştır. Mihata ve ark., 2016'da yayınladıkları biyomekanik çalışmada, 8 $\mathrm{mm}$ kalınlığındaki fasya lata greftinin $4 \mathrm{~mm}$ kalınlığındaki grefte göre subakromiyal temas basıncını daha fazla azalttığını ve humerus başının superior translasyonunu daha iyi engellediğini göstermiştir. ${ }^{[23]}$ Literatürde farklı kalınlıklardaki otojen fasya lata greftlerine ait klinik sonuçları karşılaştıran bir çalışma bulunmamakla birlikte genel kanı greft kalınlığının mümkün olduğunca $6 \mathrm{~mm}$ üzerinde tutulması yönündedir. ${ }^{[24]}$

Donör saha komplikasyonlarına ait endişeler bazı araştırmacıları SKR uygulamalarında allogreft kullanımına yönlendirmiştir. Superior kapsüler rekonstrüksiyon uygulamalarında en sık kullanılan hazır greft dermal allogreftlerdir. Birçok farklı çalışmada dermal allogreftler ile uygulanan SKR sonrası fasya lata ile uygulanan SKR sonuçlarına benzer sonuçlar elde edilmiş olmasına rağmen yapılan sistemik derlemelerde dermal allogreftlerle daha yüksek oranda greft yetmezliği görüldüğü bildirilmiştir. ${ }^{[25]}$ Mihata ve ark., 2017'de yayınladıkları biyomekanik çalışmada fasya lata otogrefti ile uygulanan SKR'nin superior glenohumeral stabiliteyi tam olarak geri kazandırmasına karşılık tek kat dermal allogreftlerin superior humeral stabiliteyi tam olarak geri kazandıramadığını göstermiştir. ${ }^{[26]}$ Bu sonuçlar araştırmacıları yeni arayışlara itmiş ve dermal allogreftlerin sonuçlarını iyileştirmeye yönelik araştırmalar başlamıştır. Güncel çalışmalarda buna yönelik dermal allogreftlerin çift kat kullanılması gündeme gelmiş ve biyomekanik çalışmalarda çift kat dermal allogreftlerin biyomekanik çalışmalarda tek kat dermal allogreftlere göre üstünlük sağladığı gösterilmiştir. ${ }^{[27,28]}$ Bu sonuçlara rağmen ne yazık ki çift kat dermal allogreftler ile uygulanan SKR'nin klinik sonuçlarıyla ilgili yayınlar henüz mevcut değildir. Superior kapsüler rekonstrüksiyon farklı araştırmacılar tarafından farklı greft tipleri kullanılarak da uygulanmaktadır. Lokal biceps tendonu ve semitendinozis tendon otogreftleri, patellar tendon ve aşil tendonu allogreftleri ve hayvan kaynaklı dermal allogreftler farklı araştırmacılar tarafından denenmesine rağmen, bu greft tiplerinin kullanımıyla ilgili literatürde kısıtlı bilgi bulunmaktadır. ${ }^{[29]}$

Günümüzde ortopedi ve travmatoloji alanındaki güncel literatür bilgileri ışığında, rotator manşet artropatisi olmayan hastalardaki onarılamaz düzeydeki rotator manşet yırtıklarında superior kapsül rekonstrüksiyonu ile kısa ve orta dönemde tatminkâr sonuçlar elde edildiği izlenmektedir. ${ }^{[30]}$ Her cerrahi teknikte olduğu gibi SKR'nin de kendine has kısıtlılıkları bulunmaktadır. Göreceli olarak yeni olan bu yöntemle ilgili bir standart uygulama tekniği ve net endikasyonlar da belirlenememiştir. Birçok hasta için kurtarıcı olabilecek bu cerrahi yöntem bu bilgiler ışığında dikkatli uygulanmalı ve hasta seçimine dikkat edilmelidir. Superior kapsül rekonstrüksiyonu ile ilgili daha fazla hasta içeren ve daha uzun soluklu çalışmalar, tartışmalı konuların açığa kavuşturulması için faydalı olacaktır.

\section{KAYNAKLAR}

1. Piper CC, Hughes AJ, Ma Y, Wang H, Neviaser AS. Operative versus nonoperative treatment for the management of full-thickness rotator cuff tears: a systematic review and meta-analysis. J Shoulder Elbow Surg 2018;27(3):572-6. Crossref

2. Bedi A, Dines J, Warren RF, Dines DM. Massive tears of the rotator cuff. J Bone Joint Surg Am 2010;92(9):1894-908. Crossref

3. Cofield RH, Parvizi J, Hoffmeyer PJ, Lanzer WL, Ilstrup DM, Rowland CM. Surgical repair of chronic rotator cuff tears. A prospective long-term study J Bone Joint Surg Am 2001;83(1):71-7. Crossref

4. Zumstein MA, Jost B, Hempel J, Hodler J, Gerber C. The clinical and structural long-term results of open repair of massive tears of the rotator cuff. J Bone Joint Surg Am 2008;90(11):2423-31. Crossref

5. Kucirek NK, Hung NJ, Wong SE. Treatment options for massive irreparable rotator cuff tears J Bone Joint Surg Am 2008;90(11):2423-31. Crossref 
6. Kovacevic D, Suriani RJ, Grawe BM, Yian EH, Gilotra MN, Hasan $\mathrm{SA}$, et al. Management of irreparable massive rotator cuff tears: a systematic review and meta-analysis of patient-reported outcomes, reoperation rates, and treatment response. J Shoulder Elbow Surg 2020;29(12):2459-75. Crossref

7. Mihata T, Lee TQ, Watanabe C, Fukunishi K, Ohue M, Tsujimura $\mathrm{T}$, et al. Clinical results of arthroscopic superior capsule reconstruction for irreparable rotator cuff tears. Arthroscopy 2013;29(3):459-70. Crossref

8. Mihata T, McGarry MH, Pirolo JM, Kinoshita M, Lee TQ. Superior capsule reconstruction to restore superior stability in irreparable rotator cuff tears: a biomechanical cadaveric study. Am J Sports Med 2012;40(10). Crossref

9. Frank RM, Cvetanovich G, Savin D, Romeo AA. Superior capsular reconstruction: indications, techniques, and clinical outcomes. JBJS Rev 2018;6(7):e10. Crossref

10. Mihata T. Editorial commentary: superior capsule reconstruction: grafts for superior capsular reconstruction must be thick and stiff. Arthroscopy 2019;35(8):2535-36. Crossref

11. Tokish JM, Makovicka JL. The superior capsular reconstruction: lessons learned and future directions. J Am Acad Orthop Surg 2020;28(13):528-37. Crossref

12. Mihata T, McGarry MH, Kahn T, Goldberg I, Neo M, Lee TQ. Biomechanical effects of acromioplasty on superior capsule reconstruction for irreparable supraspinatus tendon tears. Am J Sports Med 2016;44(1):191-7. Crossref

13. Mihata T, McGarry MH, Kahn T, Goldberg I, Neo M, Lee TQ. Biomechanical role of capsular continuity in superior capsule reconstruction for irreparable tears of the supraspinatus tendon. Am J Sports Med2016;44(6):1423-30. Crossref

14. Lavin AC, Mansour KL, Greif DN, Shallop BJ, Allegra PR, Sanchez RA, et al. Rehabilitation protocols for superior capsular reconstruction are variable: a systematic reviewArthrosc Sports Med Rehabil 2021;3(3):e919-e26. Crossref

15. Mihata T, Lee TQ, Hasegawa A, Kawakami T, Fukunishi K, Fujisawa $Y$, et al. Arthroscopic superior capsule reconstruction can eliminate pseudoparalysis in patients with irreparable rotator cuff tears. Am J Sports Med 2018;46(11):2707-16. Crossref

16. Tokish JM, Kissenberth MJ, Shanley E, Tolan SJ, Adams KJ, Alexander R, et al. Arthroscopic superior capsular reconstruction in males provides superior outcomes to reverse total shoulder or debridement for irreparable rotator cuff tears. Orthop J Sports Med 2018;6(7)(Suppl 4):2325967118S0010. Crossref

17. Burkhart SS, Denard PJ, Adams CR, Brady PC, Hartzler RU. Arthroscopic superior capsular reconstruction for massive irreparable rotator cuff repair. Arthrosc Tech 2016;5(6):e1407-e18. Crossref

18. Pennington WT, Bartz BA, Pauli JM, Walker CE, Schmidt W. Arthroscopic superior capsular reconstruction with acellular dermal allograft for the treatment of massive irreparable rotator cuff tears: short-term clinical outcomes and the radiographic parameter of superior capsular distance. Arthroscopy 2018;34(6):1764-73. Crossref
19. Pennington WT, Chen SW, Bartz BA, Pennington JM. Superior capsular reconstruction with arthroscopic rotator cuff repair in a "functional biologic augmentation" technique to treat massive atrophic rotator cuff tears. Arthrosc Tech 2019;8(5):e465-e72. Crossref

20. Burkhart SS, Hartzler RU. Superior capsular reconstruction reverses profound pseudoparalysis in patients with irreparable rotator cuff tears and minimal or no glenohumeral arthritis. Arthroscopy 2019;35(1):22-8. Crossref

21. Burkhart SS, Pranckun JJ, Hartzler RU. Superior capsular reconstruction for the operatively irreparable rotator cuff tear: clinical outcomes are maintained 2 years after surgery. Arthroscopy 2020;36(2):373-80. Crossref

22. Altintas B, Scheidt M, Kremser V, Kremser V, Boykin R, Bhatia S, et al. Superior capsule reconstruction for irreparable massive rotator cuff tears: does it make sense? A systematic review of early clinical evidence.Am J Sports Med 2020;48(13)3365-75. Crossref

23. Mihata T, McGarry MH, Kahn T, Goldberg I, Neo M, Lee TQ. Biomechanical effect of thickness and tension of fascia lata graft on glenohumeral stability for superior capsule reconstruction in irreparable supraspinatus tears. Arthroscopy 2016;32(3):418-26. Crossref

24. Lim S, AlRamadhan H, Kwak JM, Hong H, Jeon IH. Graft tears after arthroscopic superior capsule reconstruction (ASCR): pattern of failure and its correlation with clinical outcome. Arch Orthop Trauma Surg 2019;139(2). Crossref

25. Smith TJ, Gowd AK, Kunkel J, Kaplin L, Hubbard JB, Coates KE, et al. Clinical outcomes of superior capsular reconstruction for massive, irreparable rotator cuff tears: a systematic review comparing acellular dermal allograft and autograft fascia lata. Arthrosc Sports Med Rehabil 2021;3(1):e257-e68. Crossref

26. Mihata $\mathrm{T}$, Bui $\mathrm{CNH}$, Akeda $\mathrm{M}$, Cavagnaro MA, Kuenzler $\mathrm{M}$, Peterson $A B$, et al. A biomechanical cadaveric study comparing superior capsule reconstruction using fascia lata allograft with human dermal allograft for irreparable rotator cuff tear. J Shoulder Elbow Surg 2017;26(12):2158-66 Crossref

27. Cline KE, Tibone JE, Ihn H, Akeda M, Kim BS, McGarry MH, et al. Superior capsule reconstruction using fascia lata allograft compared with double- and single-layer dermal allograft: a biomechanical study. Arthroscopy 2021;37(4):1117-25. Crossref

28. Scheiderer B, Kia C, Obopilwe E, Johnson JD, Cote MP, Imhoff $\mathrm{FB}$, et al. Biomechanical effect of superior capsule reconstruction using a 3-mm and 6-mm thick acellular dermal allograft in a dynamic shoulder model. Arthroscopy 2020;36(2):355-64. Crossref

29. Kim DH, Jung YS, Kim KR, Yoon JP. The best options in superior capsular reconstruction. Clin Shoulder Elb 2021;24(2):114-21. Crossref

30. Werthel JD, Vigan M, Schoch B, Francophone Arthroscopy Society (SFA), Lädermann A, Nourissat G, et al. Superior capsular reconstruction - a systematic review and meta-analysis. Orthop Traumatol Surg Res 2021;107(8S):103072. Crossref 